Document downloaded from:

http://hdl.handle.net/10251/103625

This paper must be cited as:

Lopez-Perez, D.; Antonino-Daviu, J. (2017). Application of infrared thermography to failure detection in industrial induction motors: case stories. IEEE Transactions on Industry Applications. 53(3):1901-1908. doi:10.1109/TIA.2017.2655008

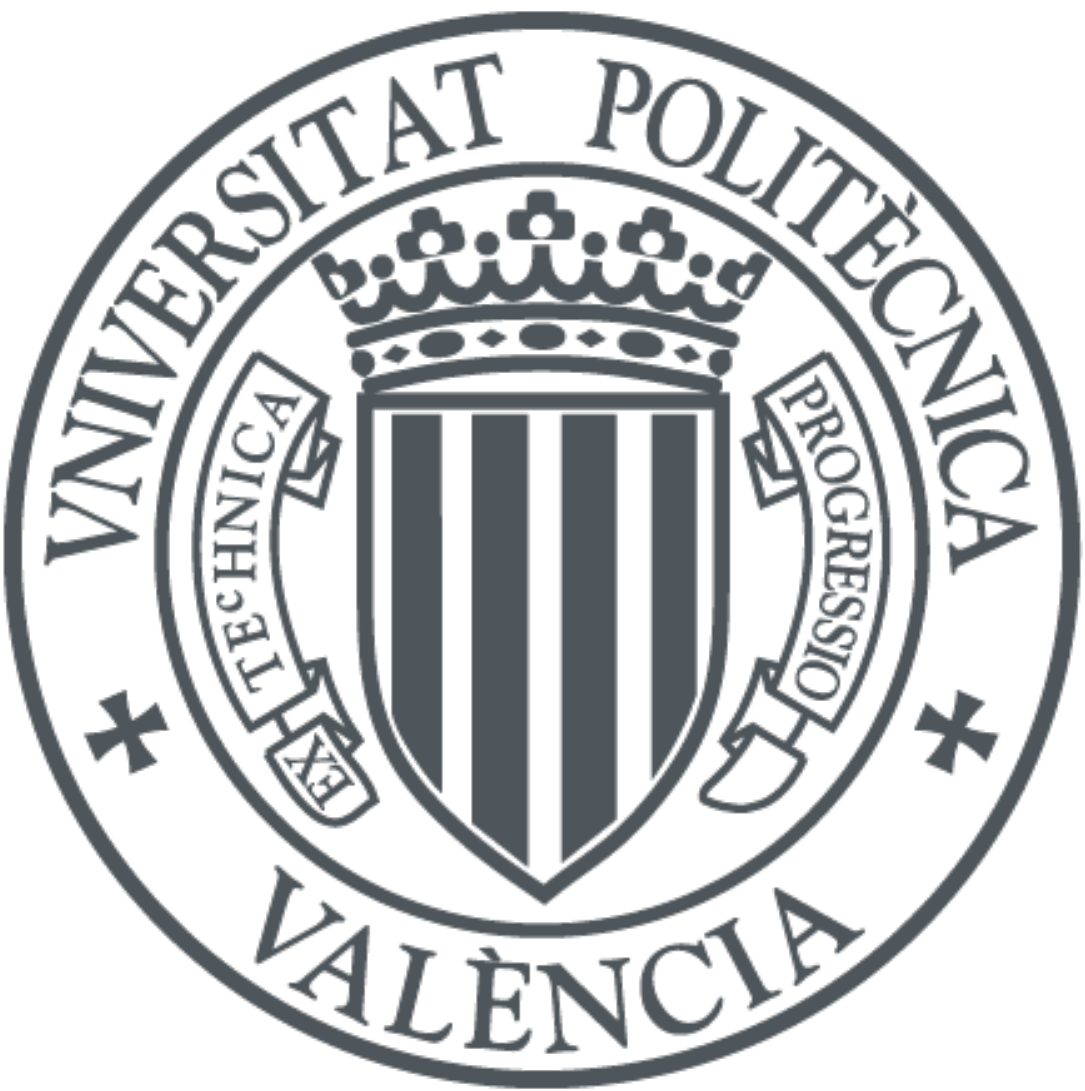

The final publication is available at

http://doi.org/10.1109/TIA.2017.2655008

Copyright Institute of Electrical and Electronics Engineers

Additional Information 


\title{
Application of infrared thermography to failure detection in industrial induction motors: case stories
}

\author{
D. Lopez-Perez and J. Antonino-Daviu
}

\begin{abstract}
Infrared thermography has been extensively applied over decades to areas such as maintenance of electrical installations. Its use in electrical machinery has been mainly circumscribed to the detection of faults in static machines, such as power transformers. However, with regard to the predictive maintenance of rotating electrical machines, its use has been much more limited. In spite of this fact, the potential of this tool, together with the progressive decrease in the price of infrared cameras, make this technique a very interesting option to, at least, complement, the diagnosis provided by other well-known techniques, such as current or vibration data analysis. In this context, infrared thermography has recently shown potential for the detection of motor failures including misalignments, cooling problems, bearing damages or connection defects. This work presents several industrial cases that help to illustrate the effectiveness of this technique for the detection of a wide range of faults in field induction motors. The data obtained with this technique made it possible to detect the presence of faults of diverse nature (electrical, mechanical, thermal and environmental); these data were very useful to either diagnose or to complement the diagnosis provided by other tools.
\end{abstract}

Index Terms - induction motors; fault diagnosis; infrared imaging; bearing faults; camera; cooling.

\section{INTRODUCTION}

I

NFRARED thermography is a well-known technique in the electrical engineering area. Over decades, it has been a very useful tool for regular inspections of electrical installations and distribution lines [1-4]; for instance, infrared cameras have been applied to the detection of defects in electrical panelboards, power cables, electric switchgear or power meters, among many others. In the area of condition monitoring of electrical machines, infrared thermography has been a preferred option for the detection of occasional faults in power transformers operating in substations, power plants and industrial facilities [5-10]. Indeed, intelligent fault diagnosis methods based on image processing have been proposed in the literature, based on the analysis of infrared images of transformers [11-12]. Excellent review works that deepen into the use of infrared thermography for electrical equipment inspection and other applications can be found in

This work was supported in part by the Spanish 'Ministerio de Economía y Competitividad' (MINECO) and FEDER program in the framework of the 'Proyectos I+D del Subprograma de Generación de Conocimiento, Programa Estatal de Fomento de la Investigación Científica y Técnica de Excelencia' (ref: DPI2014-52842-P)."

D. Lopez-Perez is with MEISA, Proyectos y Mantenimientos Eléctricos, Mecánicos y de Instrumentación, Polígono industrial SEPES, parcela 106107, 13500 Puertollano, Ciudad Real, SPAIN (e-mail: dalopezp@yahoo.es)

J. Antonino-Daviu is with the Instituto Tecnologico de la Energia, Universitat Politècnica de València, Camino de Vera s/n, 46022, Valencia, SPAIN (e-mail: joanda@die.upv.es).

\section{[1-3].}

The use of infrared thermography in the area of condition monitoring of electric motors is much more limited. In D.C. machines, infrared thermography is a useful tool to detect possible defects in the commutator as well as in the brushes system [13], which are weak points from a maintenance point of view. Furthermore, some works propose the technique for detecting faults in the field winding of such machines [13]. In wound rotor induction machines and in synchronous motors and generators, infrared data analysis can provide very interesting information about the condition of the slip ringsbrushes system, indicating possible asymmetries or defective contacts [14]. For most of these machines, infrared thermography is commonly used in standard off-line tests, as the core ring test (or loop test) to detect core inter-laminar insulation failures [15]. However, in general terms, the application of this technique has been often circumscribed to the detection of defective connections, usually external to the machine itself [16-17]; the infrared technique has been also used to detect problems such as shaft misalignments [26]. Some works have even widened the use of infrared thermography to analyzing the effect of possible motor faults on the kinematic chain [27], while other have proposed the incorporation of this technique in regular maintenance and inspection of electric motors [28] .

In spite of the previous facts, infrared thermography seems a very interesting option taking into consideration that most of the motor faults usually lead to temperature rises (either general or located in specific regions) that may be detected via infrared data analysis. On the other hand, despite infrared cameras came with excessively high costs only a few years ago, today there are infrared data acquisition devices with very affordable prices and with advanced features (such as high image resolution or possibility of acquiring images during transient regimes). These facts confer this technique with a huge potential, since it can easily become an excellent information source for the condition monitoring of rotating electrical machines. In the case of induction motors, the technique may be very useful, especially for large induction motors, the cost of which can easily amount to \$1-2 million and whose unexpected failures can entail losses of several million \$ [18]. In these machines, the infrared thermography may play an excellent role to diagnose certain failures or to complement the diagnostic conclusions obtained with other techniques such as vibration or current data analysis $[19,20]$, as will be shown in this paper.

As a matter of fact, recent works have proposed the combination of infrared data analysis with the analysis of currents (both in steady-state and in transient regime) in order to reach a more reliable conclusion about the condition of 
certain parts of the machine [20]. In these works, it was proven, via laboratory tests, that the infrared thermography technique could be especially useful for the complementary diagnosis of bearing failures or cooling problems, among others.

This paper presents several case studies referred to the use of infrared thermography in field motors operating in a petrochemical plant [21]. The results included here are a part of a more general study that was intended to diagnose the condition of a set of motors with different sizes and operating conditions; in twenty of them, the infrared technique was showing evidence of diverse anomalies. The interesting conclusions of the study revealed that the infrared technique was able to diagnose or provide very useful information for the diagnosis of faults of very different nature such as bearing lubrication problems, incorrect belt tightening, deficient cooling, damaged bearings or defective connections, among others. The paper is structured as follows: Section II reviews the foundation of the infrared thermography technique; Section III presents the results obtained after applying the technique to the field motors as well as the discussion of these results; finally, in Section IV, the conclusions of the work are summarized.

\section{INFRARED THERMOGRAPHY}

Basically, the infrared thermography technique allows the visualization of the superficial temperatures of an object with high resolution and in a non-invasive way, i.e., not needing any contact with the object [20]. The physical basis of the method relies on turning infrared radiation measurements (captured via an infrared detector) into temperature measurements. This is carried out by measuring the radiation emitted by the object surface within the infrared portion of the electromagnetic spectrum and by subsequently translating these measurements into electrical signals. The infrared detectors are the core of the infrared thermography systems which are classified into different categories (thermal vs. semiconductor) depending on the detector employed [1]. An infrared camera basically consists of the optical components (lens, mirrors, etc.), detector elements, cooling system and associated electronics [1]. Infrared cameras have strongly evolved over the last few decades, from the initial versions based on scanning mirrors to modern models relying on focal plane arrays (FPA) [1, 30-31]. An excellent revision of the operation of different infrared sensors, as well as of the available technology in the field can be found in [32].

As mentioned in [3], there are certain factors that exert influence when applying the infrared thermography technique. These factors can be classified into procedural (which concern the thermographer), technical (emissivity of the inspected equipment, load variation, distance from the inspected object, infrared camera specifications) and environmental (ambient temperature, humidity, wind or other convection, solar radiation, etc...) [3]. All these factors should be considered when carrying out an inspection even if the temperatures can be measured accurately [34]. An interesting analysis of the influence of each particular factor under a practical perspective can be found in [3].

According to the energy source over which the infrared inspection is carried out, two possible infrared readings exist: direct and indirect. Direct readings are obtained when measuring the radiation from the main energy source point while indirect readings are those that are done in neighboring or close points, where the heat has been transmitted via conduction, radiation or convection. Some authors define direct readings as those where there is little or no thermal insulation between the infrared camera and the energy source, while indirect readings are those where there is a considerable thermal insulation between both elements [22]. Fig. 1 illustrates the differences between direct (Fig. 1 (a)) and indirect (Fig. 1 (b)) infrared thermography.

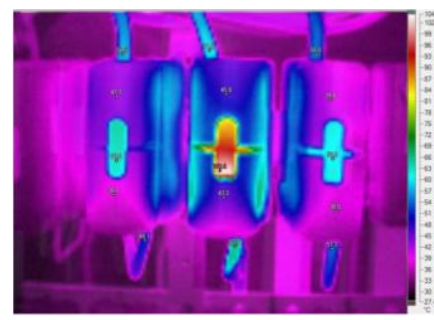

(a)

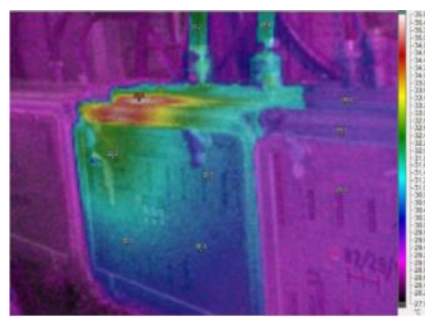

(b)
Fig. 1. Direct (a) versus Indirect (b) infrared readings.

On the whole, dynamic equipment or components, such as motors, bearings, gear reducers, etc... are analyzed via indirect infrared readings since the fault is started inside the equipment. Hence, it is necessary to assess these elements by taking into consideration both constructive, environmental and operational aspects in order to determine incorrect temperatures or heat transfer trends or patterns that would inform about the presence of developing failures. Fig. 2 shows an example of the evolution of the measured temperature values (weekly intervals) by means of direct and indirect infrared readings for the same fault.

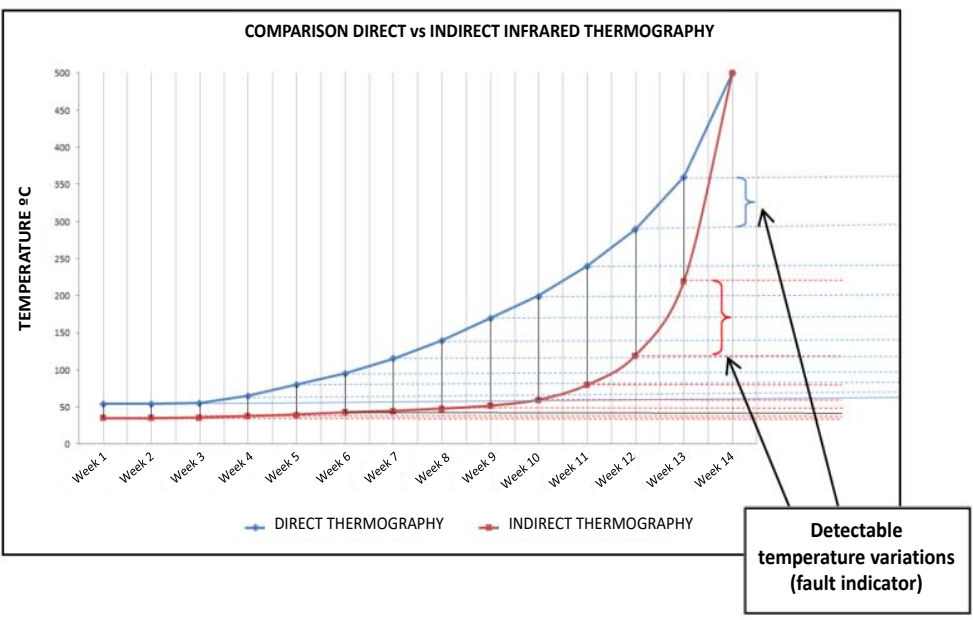

Fig. 2. Direct and Indirect thermography curves.

In order to clearly confirm the presence of the fault, a fault indicator based on infrared thermography must be established so that it must be robust enough to be able to set a reliable alarm threshold and it must show a progressive variation versus the evolution trend that enables to establish appropriate time intervals between successive measurements. In general, indirect infrared readings have fault indicators that show exponential evolutions, so if the time intervals between 
successive measurements are too long, the fault can develop before it is detected.

With regard to the fault indicator, there are two ways of applying the infrared thermography to rotating electrical equipment: quantitative and qualitative [3]. The first one considers the fault indicator in absolute terms (i.e. absolute temperature of the equipment) while the second one considers relative temperature values of a point with regard to other parts under similar operating conditions [3]. Qualitative infrared analysis is widespread in many industrial applications [34] and, often, it relies on the use of the $\Delta \mathrm{T}$ criterion [35-36] which, according to the NETA Standard [37], evaluates the temperature rise above a defined reference that can be either the ambient air temperature, the temperature of an analogue component under similar conditions or the maximum permitted temperature of the component [3] Depending on the obtained $\Delta \mathrm{T}$, a recommended maintenance action is given (see, for instance Table I, which displays the suggested actions based on the temperature rise according to the NETA standard [37]). Other available standards such as ASTM-E1934 [38] or NFPA70-B [39] also provide equivalent guidelines for infrared inspection.

TABLE I. THERMOGRAPHIC SURVEY SUGGESTED ACTIONS BASED ON $\triangle$ T IN ELECTRICAL EQUIPMENT ACCORDING TO NETA [37]

\begin{tabular}{|c|c|c|}
\hline $\begin{array}{c}\text { Temperature } \\
\text { difference }(\Delta \mathbf{T}) \text { based } \\
\text { on comparisons } \\
\text { between similar } \\
\text { components under } \\
\text { similar loading. }\end{array}$ & $\begin{array}{c}\text { Temperature } \\
\text { difference }(\Delta \mathbf{T}) \text { based } \\
\text { upon comparisons } \\
\text { between } \\
\text { component and } \\
\text { ambient air } \\
\text { temperatures. }\end{array}$ & $\begin{array}{c}\text { Recommended } \\
\text { Action }\end{array}$ \\
\hline $1^{\circ} \mathrm{C}-3^{\circ} \mathrm{C}$ & $1^{\circ} \mathrm{C}-10^{\circ} \mathrm{C}$ & $\begin{array}{c}\text { Possible deficiency; } \\
\text { warrants } \\
\text { investigation }\end{array}$ \\
\hline $4^{\circ} \mathrm{C}-15^{\circ} \mathrm{C}$ & $11^{\circ} \mathrm{C}-20^{\circ} \mathrm{C}$ & $\begin{array}{c}\text { Indicates probable } \\
\text { deficiency; repair } \\
\text { as time permits }\end{array}$ \\
\hline---- & $21^{\circ} \mathrm{C}-40^{\circ} \mathrm{C}$ & $\begin{array}{c}\text { Monitor until } \\
\text { corrective measures } \\
\text { can be accomplished }\end{array}$ \\
\hline$>15^{\circ} \mathrm{C}$ & $>40^{\circ} \mathrm{C}$ & $\begin{array}{c}\text { Major discrepancy; } \\
\text { repair } \\
\text { immediately }\end{array}$ \\
\hline
\end{tabular}

Qualitative infrared analysis has provided good results for inspection of electrical equipment, especially switchgear, cables or static machines. In these cases, comparison with other components under similar operating conditions is often feasible. As [3] points out, the advantage of qualitative thermography is that it is a practical procedure to establish whether or not there is a failure and, also, whether the emissivity has a minor impact on the results [35].

However, in the case of rotating electrical machines, such as electric motors, its application may not be so straightforward. In electric motors, the temperature rise (alarm threshold) to consider if there is failure or not will vary depending on a number of factors related to both the constructive characteristics of the machine and the operational conditions; each machine or component may have different temperature alarm thresholds. More specifically, the qualitative infrared-based diagnosis of electric motors will be based on factors such as: threshold values defined by the manufacturer, duty cycle, environmental factors, operation conditions (load, supply voltage, etc...) and previous experience. Some thermographers prefer to build their own testing specification chart based on their experience, which can be partially based on the available standards [3].

In the present work, the set of motors that were inspected were operating under rather stable conditions (both environmental and operating) and their sizes were rather similar. This allowed the plant engineers to establish some approximate temperature thresholds for each motor part or component (see Table II). These thresholds were approximately based on the $\Delta \mathrm{T}$ criterion guidelines shown in Table I. If these alarm thresholds were surpassed, this would become an indication of a possible anomaly in the motor, so that further analysis should be carried out.

Note that, in many cases, the temperature distribution of the surface -thermal pattern- also gives very important information; sometimes, although the temperature thresholds are not surpassed, the thermal pattern can inform on the development of a certain fault in the motor. In this regard, the experience of the thermographer plays an important role for detecting these deviations in the thermal patterns in comparison with previous inspections.

TABLE II. GENERAL ALARM THRESHOLDS ADOPTED FOR DIFFERENT DIAGNOSED COMPONENTS OF THIS WORK BASED ON OWN AUTHORS EXPERIENCE

\begin{tabular}{|c|c|}
\hline Element & Temperature Threshold \\
\hline Motor frame & $>70^{\circ} \mathrm{C}$ \\
\hline Gears (reducers, multipliers, etc..) & $>80^{\circ} \mathrm{C}$ \\
\hline Bearings & $>70^{\circ} \mathrm{C}$ \\
\hline Couplings & $>80^{\circ} \mathrm{C}$ \\
\hline Belt transmissions & $>90^{\circ} \mathrm{C}$ \\
\hline
\end{tabular}

All the previous facts show the potential of the infrared thermography technique to indicate an abnormal operation of certain parts of the machine, which can indicate a fault or can advise the application of other techniques (currents, vibrations) to confirm the presence of the damage. There are four main possible sources of abnormal temperature values or irregular heat transmission patterns: electrical, mechanical, environmental or thermal. Each of them can respond to different faults or anomalies in the machine, as shown in Table III [25]. Therefore, the potential range of failures or anomalies that may be detectable with infrared thermography is of unquestionable value to consider it an interesting information source for the diagnosis.

TABLE III. SOURCES OF ABNORMAL TEMPERATURES AND THEIR POSSIBLE CAUSES

\begin{tabular}{|c|l|}
\hline Origin & \multicolumn{1}{c|}{ Fault/anomaly } \\
\hline Electrical & $\begin{array}{l}\text { Harmonic distortion, voltage unbalances, } \\
\text { incorrect supply voltage, erroneous motor } \\
\text { selection, connection defects, shorted turns, } \\
\text { broken rotor bars... }\end{array}$ \\
\hline Mechanical & $\begin{array}{l}\text { Misalignment, operational overload, } \\
\text { transmission problems, bearing faults with } \\
\text { thermal emission... }\end{array}$ \\
\hline Environmental & $\begin{array}{l}\text { Dust, winding insulation humidity, lubricant } \\
\text { contamination, dirtiness... }\end{array}$ \\
\hline Thermal & $\begin{array}{l}\text { Deficient cooling, incorrect lubricant } \\
\text { refrigeration... }\end{array}$ \\
\hline
\end{tabular}




\section{CASE STORIES: APPLICATION TO FIELD MOTORS}

A survey was carried out based on the infrared inspection of a group of motors operating in a petrochemical plant. In twenty of these machines, the infrared thermography technique was showing the presence of abnormal temperature values or irregular thermal patterns that informed about the presence of diverse types of anomalies and faults. These anomalies had different origin, namely; twelve were attributed to mechanical problems (deficient bearing lubrication (8), damaged bearings (1), deficient belt tightening (1) and operational overload (2)), six were due to electrical causes (defective connections (4), winding problems (1) and rotor damages (1)), five had thermal origin (obstructed cooling channels (5)), and one was due to environmental factors (oil contamination).

In this section, the most representative cases are detailed; they help to illustrate the potential of the infrared thermography for the detection of different types of failures and anomalies. All measurements were taken with the same infrared camera (model Fluke Ti-100) and maintaining similar distances with respect to the analyzed machine in successive revisions. The motors included in this paper were operating at a fixed speed and were operating at rated conditions during the inspections. The room temperature was registered in each measurement so that the measured values could be properly normalized. On the other hand, the emissivity in each case was calculated using a tape with known emissivity obtaining an approximate value of 0.94 .

\section{A. Motor 1: Lubricating pump motor (deficient cooling)}

This motor was a L.V. machine that was driving a pump for bearing lubrication. The infrared inspection revealed a motor overheating, since the frame temperatures were reaching values above $70^{\circ} \mathrm{C}$ in some points (Fig. 3). After a more detailed analysis of the motor, it was observed that the cooling air flow was insufficient; the cause was an obstruction of the cooling channels that was produced by product wastes. The cooling channels and fins were properly cleaned and the subsequent infrared inspection revealed an abrupt decrease in motor frame temperatures up to values around $30-40^{\circ} \mathrm{C}$ with the motor operating under similar conditions as in the first inspection (see Fig. 4). Hence, in this case, infrared thermography enabled to detect the source of the problem.

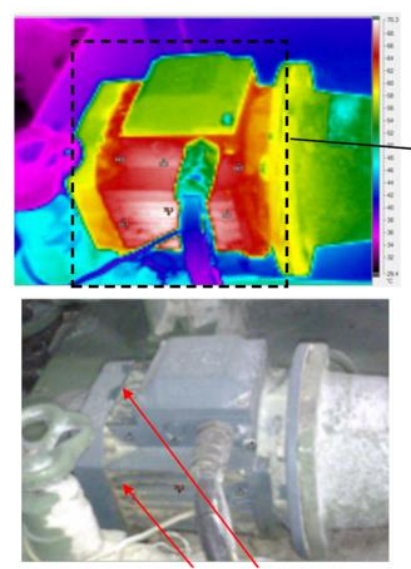

Obstructed cooling channels

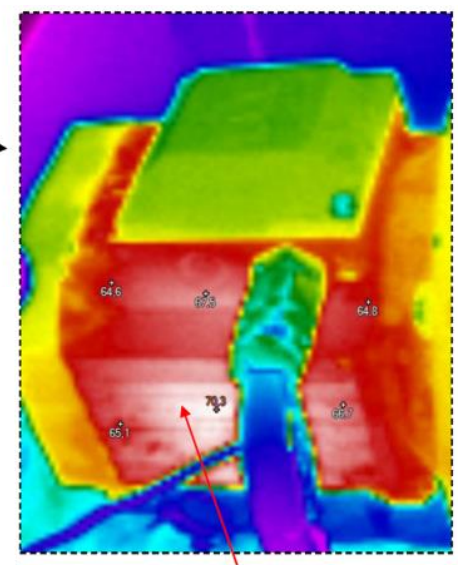

Abnormal temperatures on the motor frame. Origin of the fault: deficient cooling
Fig. 3. Infrared inspection of Motor 1: deficient cooling.
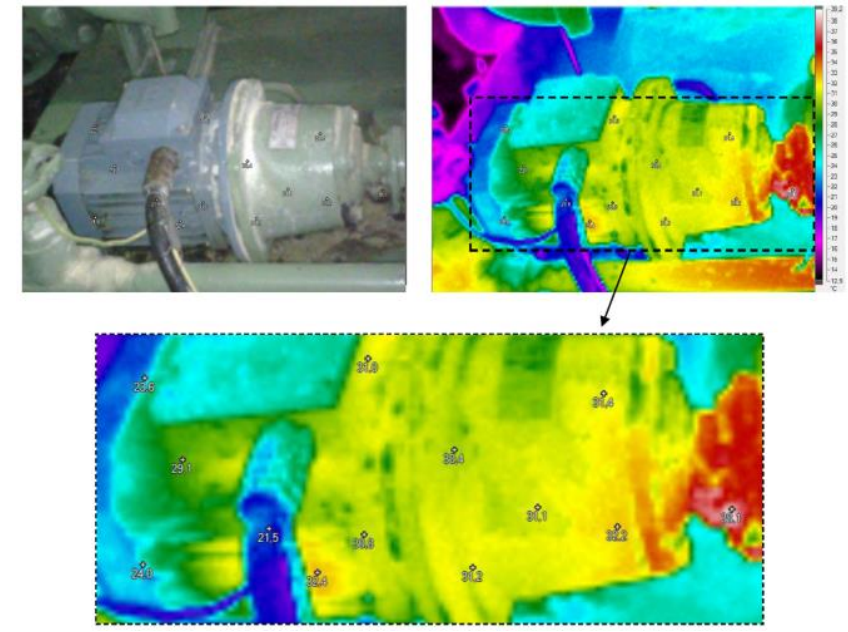

Fig. 4. Infrared inspection of Motor 1 after cleaning.

\section{B. Motor 2: Blower motor (deficient bearing lubrication)}

In this case, the inspected element was a bearing of a motor that was driving a blower. An initial infrared inspection revealed an excessive heating of the bearing. This can be noted in Fig. 5 which shows superficial temperatures above $90^{\circ} \mathrm{C}$ (and even $100^{\circ} \mathrm{C}$ ) in the bearing region. We can also observe the deposit of product waste over the bearing cage. The bearing was properly cleaned and a new inspection was carried out. However, no significant temperature drop was detected. Therefore, it was finally decided to re-lubricate the bearing. This measure was much more effective, as a new infrared inspection revealed: the temperatures were not higher than $60^{\circ} \mathrm{C}$ in the bearing region for the motor operating under similar conditions (Fig. 6).

It is important to emphasize that, in the past, this motor had an episode of catastrophic failure caused by problems in the bearings: in 2010, the lack of proper bearing lubrication was not properly detected via vibration analysis; finally, this fact led to the collapse of the bearings and to the damage of the stator insulation (see Fig 7). This is an illustrative case that shows how the infrared thermography may provide very interesting information for the diagnosis in situations where other techniques may fail.

In order to prevent the occurrence of this type of bearing lubrication problems, the plant engineers proposed not only the use of the infrared technique to detect such anomalies in advance, but they also suggested the lubrication of the bearings by means of ultrasounds; this lubrication method may bring interesting benefits, such as the reduction of the possibility of an inexact lubrication, amongst others. Moreover, the accurate study of this failure enabled to plot a P-F curve associated with bearing faults; this curve shows, for the corresponding fault, the minimum detectable alarm level for each considered technique. This curve is plotted in Fig. 8 and shows how primary bearing defects (wear, indentations, smearing, corrosion...) are best detected via infrared thermography and ultrasounds while vibrations and oil analysis are best suited for the detection of secondary defects. 

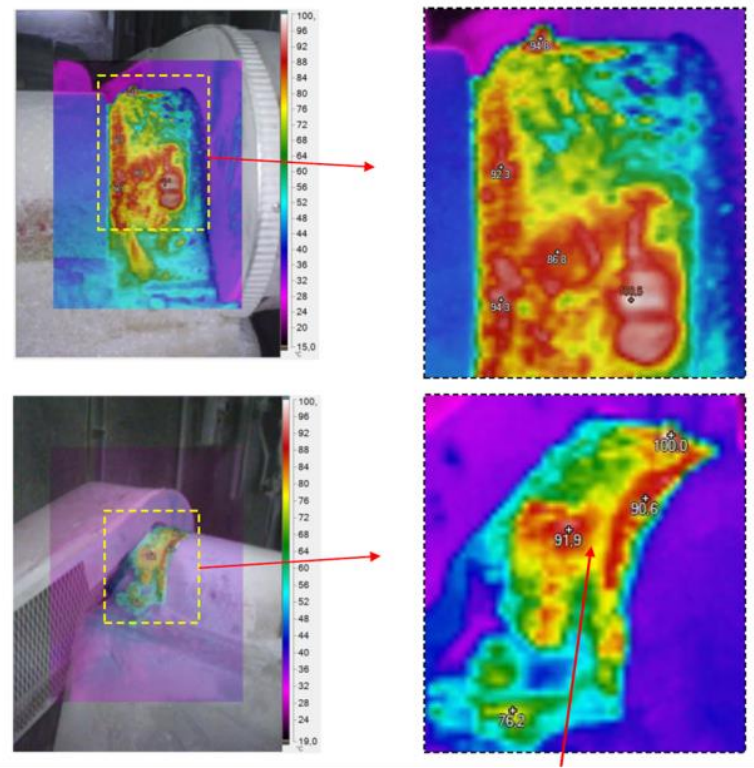

Abnormal temperatures on the bearing region. Origin of the fault: deficient bearing lubrication

Fig. 5. Infrared inspection of bearing of Motor 2: deficient bearing lubrication.
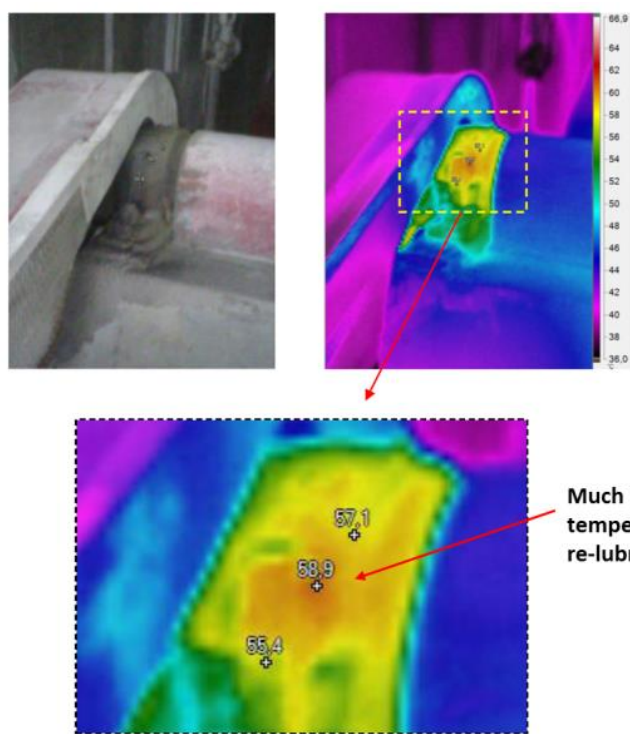

Much lower

temperatures after re-lubrication

Fig. 6. Infrared inspection of bearing of Motor 2 after re-lubrication.

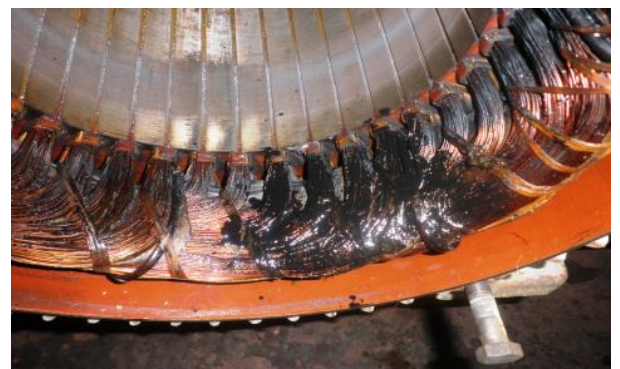

Fig. 7. Insulation damage occurred in 2010 in the same motor due to catastrophic failure of the bearings.

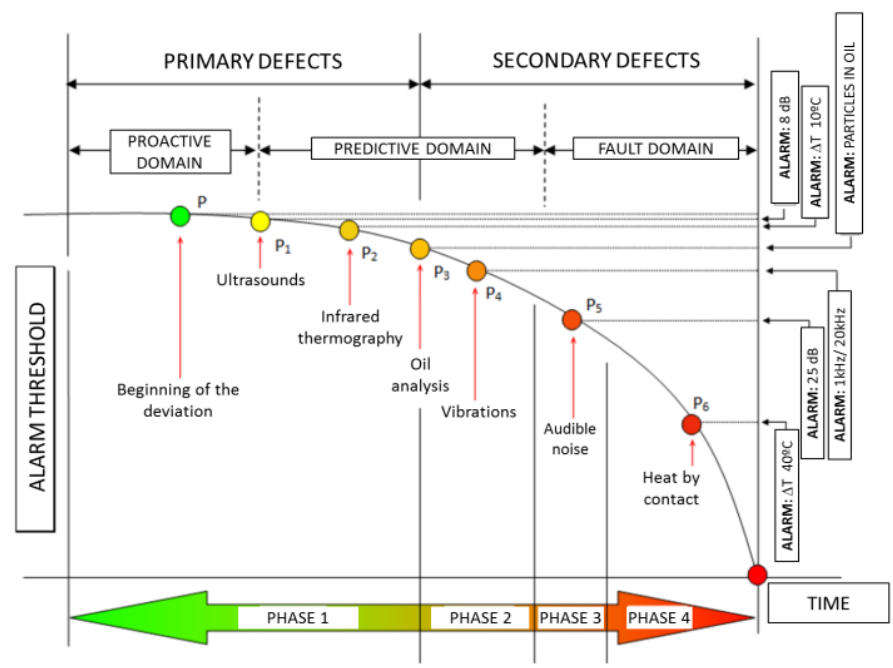

Fig. 8. Developed P-F curve for bearing faults as a function of alarm levels

Anyway, this field case has shown the usefulness of the infrared technique to detect bearing problems that lead to abnormal levels of heat transmission. This was also proven by another of the field inspections carried out in the survey which enabled to detect similar faults in other bearings.

\section{Motor 3: Deodorization fan motor (insufficient belt tightening)}

The inspected motor in this case was an L.V. machine driving a fan for deodorization purposes. Oddly enough, the infrared inspection revealed a very high heat dissipation in the belt transmission system (see Fig. 9), with a maximum temperature of $129.8{ }^{\circ} \mathrm{C}$ that was read on the pulley. The deficient tension leads to belt slip on the pulley and increases the heat dissipation due to the friction, which results in decreased efficiency and a reduction of the belt service life.

To solve the problem, the belts were properly tightened and, afterwards, a new inspection was carried out. Fig. 10 shows the new thermal map after the belt tightening that reveals much lower temperatures in the transmission system $\left(30^{\circ} \mathrm{C}\right.$ in average lower than in the previous case).
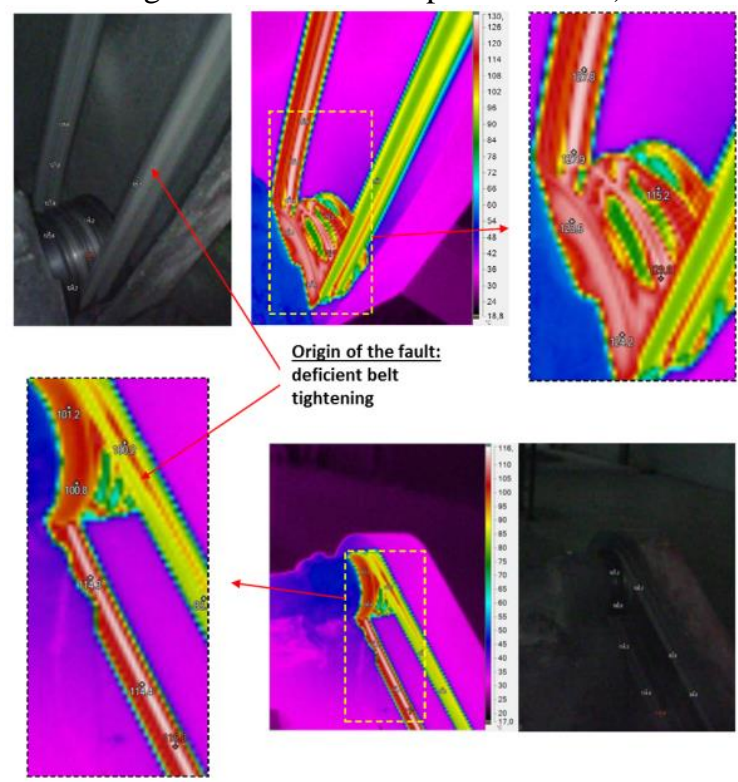

Origin of the fault: deficient be
tightening
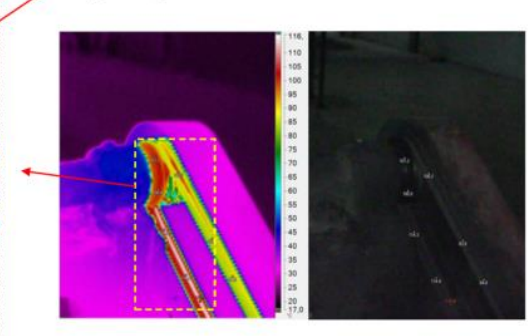

Fig. 9. Infrared inspection of Motor 3: deficient belt tightening. 




Fig. 10. Infrared inspection of Motor 3 after belt tightening.

\section{D.Motor 4: Motor driving a blower (defective connection)}

The inspected motor was an L.V. machine driving a blower. The infrared inspection revealed an excessive heat dissipation that was localized in the upper part of the frame, close to the motor terminal connection box, as shown in Fig. 11 . The temperatures there reached high values $\left(76.8^{\circ} \mathrm{C}\right)$.

While the motor was switched-off, the winding resistances were measured, obtaining very similar values. The connections were checked and a weak connection was found as well as a partial damage in one of the terminals (Fig. 10, top). After replacement of the terminal and after fixing the connections, the new infrared inspection showed lower temperature values (Fig. 12, bottom).
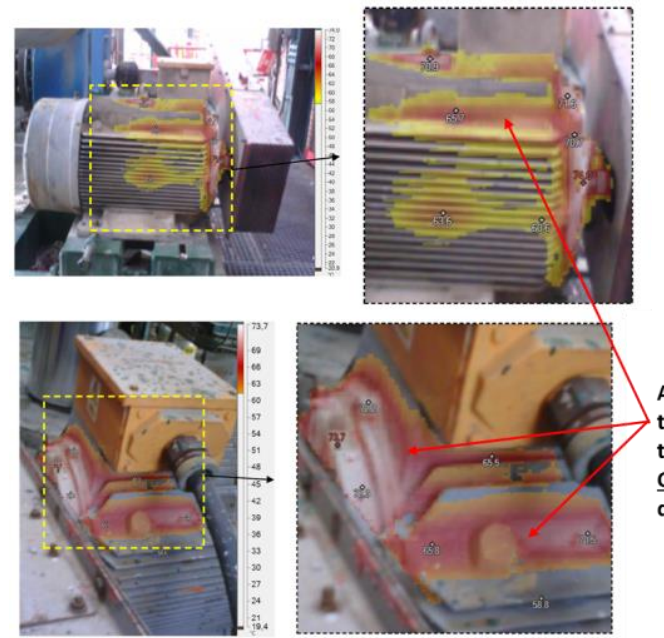

Abnormal

temperatures near

the connections box. Origin of the fault: defective connection
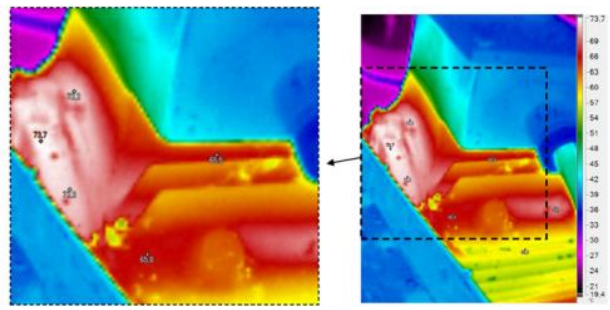

Fig. 11. Infrared inspection of Motor 4: defective connection.
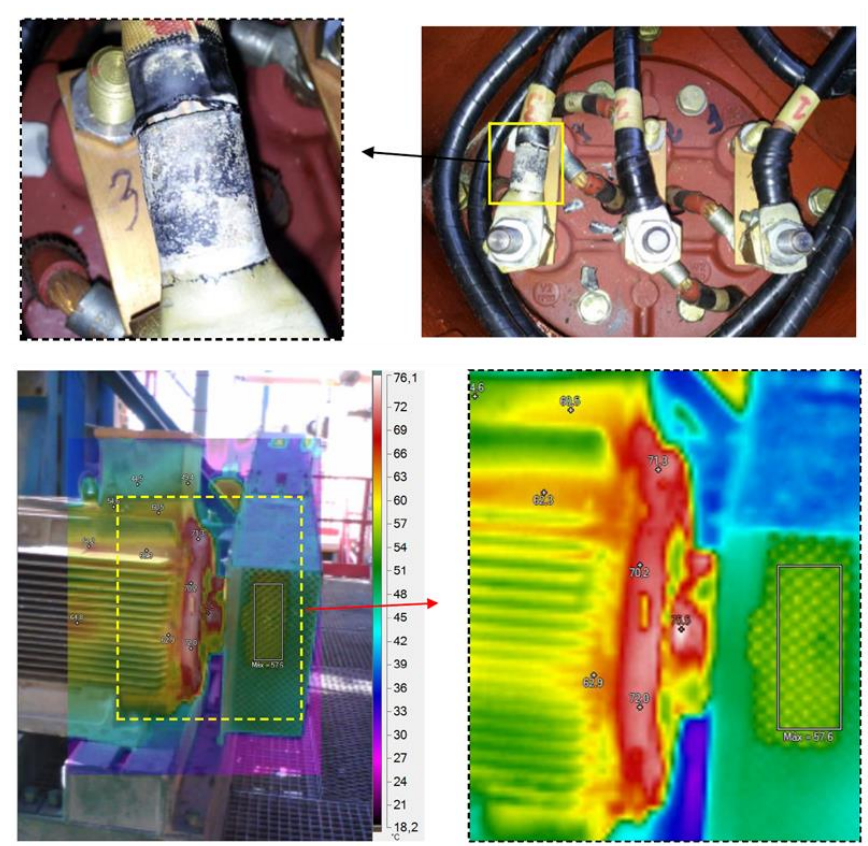

Fig. 12. Defective connection and terminal in motor connection box (top) and Infrared inspection of Motor 4 after repair (bottom).

\section{E. Motor 5: Cooling tower fan motor (winding asymmetry)}

In this case, the considered motor was driving a fan of a cooling tower. The infrared inspection of that motor (Fig. 13) showed a significant heating in the motor frame $\left(85.2^{\circ} \mathrm{C}\right.$ in the surface and, probably, above $100{ }^{\circ} \mathrm{C}$ inside the motor). No cooling anomalies were found during the inspection. As a first measure, the bearings were re-lubricated and repaired in a workshop but no temperature drop was observed.

Then, the motor terminal box was inspected and only a little temperature difference between connections was found. The winding resistance of each phase was measured with an ohmmeter and the results were very interesting (see Table IV, which compiles the results of the measurements): a significant winding asymmetry was detected between phases, leading to a Max Delta $\mathrm{R}$ value of near 9\%. This could indicate internal high resistance connections, broken turns or internal shorts. This may be the potential cause of the abnormal heat dissipation. A motor re-winding was finally suggested.

Hence, the advantage of the technique in this case is that it informed about the existence of an anomaly in the stator winding, suggesting the adoption of further maintenance actions. Note that these anomalies are not always easily detectable with other techniques (e.g. current analysis), therefore, the information provided by infrared thermography may be very interesting to prevent eventual catastrophic consequences.

TABLE IV. MEASURED VALUES OF WINDING RESISTANCE IN EACH PHASE

\begin{tabular}{|c|c|}
\hline Resistance & Measured value \\
\hline$R_{R}$ & $87.80 \mathrm{~m} \Omega$ \\
\hline$R_{S}$ & $100.04 \mathrm{~m} \Omega$ \\
\hline$R_{T}$ & $87.70 \mathrm{~m} \Omega$ \\
\hline
\end{tabular}




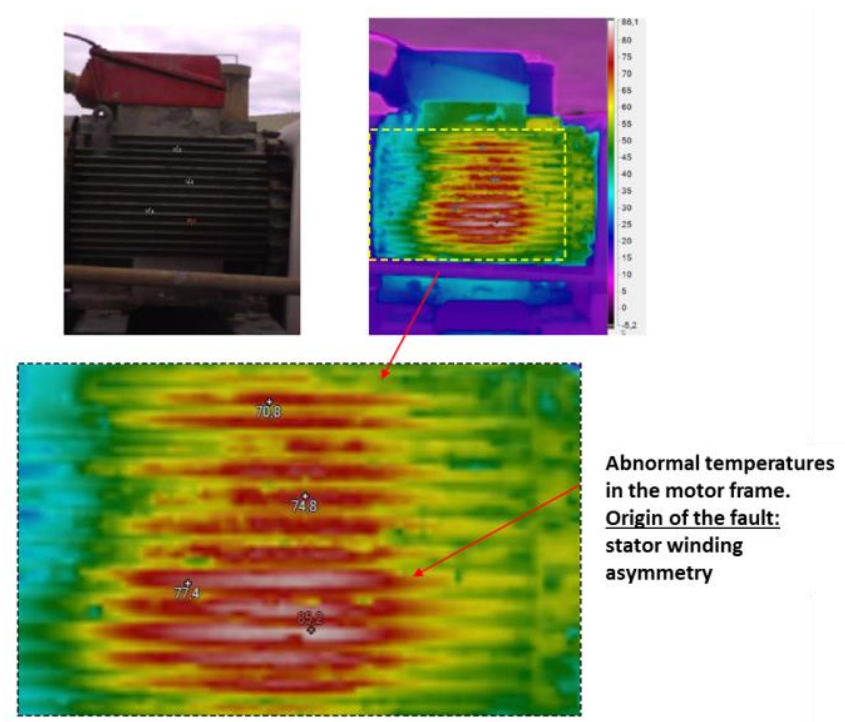

Fig. 13. Infrared inspection of Motor 5: winding asymmetry.

\section{CONCLUSIONS}

Infrared thermography is a well-known technique in the electrical engineering area. However, its industrial use in the area of condition monitoring of induction motors is still scarce. This is not coherent with the extraordinary potential of this technique that can provide very useful information about the presence of different faults in machines; this may be very useful to either determine the motor health when there is no other diagnostic method available or to complement the diagnosis provided by other techniques (currents/vibrations analysis).

This work has presented some industrial case stories extracted from a more general survey that was carried out in induction motors operating in a petrochemical plant. The infrared inspections of these motors enabled to detect several types of failures in the inspected motors that had rather different causes. The results and discussions included here show that this technique was able to detect faults such as bearing lubrication failures, problems in the transmission system, defective connections, cooling system problems and even to give some clues about the presence of stator winding problems. Note that, in most of the analyzed cases, the study of alternative quantities, such as vibrations or currents, did not make it possible to detect the presence of the anomaly in the machine, a fact that, in the past, led to failures of catastrophic consequences. All these results prove the potential of this technique and the importance of incorporating it within induction motor predictive maintenance programs.

Note that every technique (current, vibration analysis...) is likely to create false alarms caused by a variety reasons, and infrared thermography is not an exception. In this sense, motor overheating can be caused by reasons that are not related to a fault, such as operational overload. However, even under these conditions, previous works [19-20] have reported the appearance of different thermal patterns that can be used to discriminate between motor failures and other anomalies that are not related to the motor. In this regard, the thermographer expertise to interpret the thermal images accurately plays a crucial role; in order to avoid this dependence on the user, expert systems based on artificial intelligence techniques are being developed to enable an automatic interpretation of infrared images and reach a diagnosis of the condition discriminating between faults and other effects [29].

Future works will deal with the analysis of the robustness and reliability of the proposed strategy with respect to uncertainty and disturbance affecting the monitored processes, taking into consideration the issues explained in [23-24], among others.

\section{ACKNOWLEDGMENT}

The authors wish to thank Ms. Gema Fernández Romero for her thorough proofreading of the manuscript.

\section{REFERENCES}

[1] S. Bagavathiappan, B.B. Lahiri, T. Saravanan, John Philip, T. Jayakumar, "Infrared thermography for condition monitoring - A review," Infrared Physics \& Technology, vol. 60, pp. 35-55, Sep. 2013

[2] R. Gade, T.B. Moeslund, "Thermal cameras and applications: a survey," Machine Vision and Applications, vol. 25, no. 1, pp. 245-262, Nov. 2013.

[3] M. S. Jadin, S. Taib, "Recent progress in diagnosing the reliability of electrical equipment by using infrared thermography," Infrared Physics \& Technology, vol. 55, no. 4, pp. 236-245, July 2012.

[4] A.S. Nazmul Huda, S. Taib, M. S. Jadin, D. Ishak, "A semi-automatic approach for thermographic inspection of electrical installations within buildings," Energy and Buildings, vol. 55, pp. 585-591, Dec. 2012.

[5] M. Wang, A. J. Vandermaar and K. D. Srivastava, "Review of condition assessment of power transformers in service," in IEEE Electrical Insulation Magazine, vol. 18, no. 6, pp. 12-25, Nov.-Dec. 2002.

[6] N.Y. Utami, Y. Tamsir, A. Pharmatrisanti, H. Gumilang, B. Cahyono and R. Siregar, "Evaluation condition of transformer based on infrared thermography results," IEEE 9th International Conference on the Properties and Applications of Dielectric Materials, Harbin, China, July 2009.

[7] J.W. Harley, "CIGRÉ Working Group 12.18 TF02, Survey on diagnostics \& monitoring techniques transformer subsystems," presented at CIGRÉ SC 12, Sydney Colloquium, Australia, 1997.

[8] G. Duke, "Predictive maintenance a case study in infrared thermography," Electrical Maintenance, pp. 11-12, 1998.

[9] M. Weiping et al, "Fault Diagnosis on Power Transformers using nonelectric Method," IEEE ISIE, Montréal, Quebec, Canada, 9-12 July, 2006.

[10] J.C. Pearson and D.A. Pandya, "Utilizing Infrared and Power Quality Techniques to Diagnose and Re-Commission 33 old Power, Lighting \& Receptacles Panels and Distribution Transformers at the New Jersey International \& Bulk Mail Center," Electrical Insulation Conference and Electrical Manufacturing Expo, 2007.

[11] A. Abu-Siada and S. Islam, "Image processing-based on-line technique to detect power transformer winding faults," in proc. of the 39th Annual Conference of the IEEE Industrial Electronics Society, IECON 2013, Vienna, 2013, pp. 5549-5554.

[12] Y-C. Chou, L. Yao, "Automatic Diagnosis System of Electrical Equipment using Infrared Thermography" in proc. of the 2009 International Conference of Soft Computing and Pattern Recognition, Malacca. Malaysia, Dec. 2009, pp. 155-160.

[13] M. Manana, A. Arroyo, A. Ortiz, C.J. Renedo, S. Perez, F. Delgado, "Field winding fault diagnosis in DC motors during manufacturing using thermal monitoring," Applied Thermal Engineering, vol. 31, no.5, pp. 978-983, Apr 2011.

[14] P. Gill, Electrical Power Equipment Maintenance and Testing, Second Edition, CRC Press, Taylor \& Francis Group, U.S., 2009.

[15] S.B. Lee, E. Wiedenbrug., K. Younsi, "ECCE 2013 Tutorial: Testing and Diagnostics of Induction Machines in an Industrial Environment", presented at ECCE 2013, Denver, CO, USA, Sep 2013. 
[16] J. Yoo, J. Yun and S.B. Lee, "Automated Monitoring of HighResistance Connections in the Electrical Distribution System of Industrial Facilities," IEEE Transactions on Industry Applications, vol. 45, no. 2, Apr. 2009.

[17] J. Bockstette, E. Stolz and E. Wiedenbrug, "Upstream Impedance Diagnostic for Three Phase Induction Motors," IEEE International Symposium on Diagnostics for Electric Machines, Power Electronics \& Drives, SDEMPED 2007, Krakow, Poland.

[18] C. Yang, T-J. Kang, D. Hyun, S. Lee, J. Antonino-Daviu, J. PonsLlinares, "Reliable Detection of Induction Motor Rotor Faults Under the Rotor Axial Air Duct Influence," IEEE Trans. Ind. Appl., vol. 50, no. 4, pp. 2493-2502, Jul.-Aug. 2014.

[19] M.J. Picazo-Ródenas, R. Royo, J. Antonino-Daviu, J. Roger-Folch, "Use of the infrared data for heating curve computation in induction motors: Application to fault diagnosis," Engineering Failure Analysis, Volume 35, 15 December 2013, Pages 178-192

[20] M.J. Picazo-Rodenas, J. Antonino-Daviu, V. Climente-Alarcon, R. Royo-Pastor, A. Mota-Villar, "Combination of Noninvasive Approaches for General Assessment of Induction Motors," IEEE Transactions on Industry Applications, vol.51, no.3, pp.2172-2180, May/Jun. 2015.

[21] D. López-Pérez, J. Antonino-Daviu, "Application of infrared thermography to fault detection in industrial induction motors: case stories," in proceedings of the International Conference of Electrical Machines (ICEM 2016), Lausanne, Switzerland, Sep.2016.

[22] T. Scanlon, "Thermal Inspections Prove Effective for Substation Maintenance, Safety", Power Grid International, vol. 10, no. 3, 2005. Available at http://www.elp.com.

[23] J. Chen, and R. J. Patton Robust Model-Based Fault Diagnosis for Dynamic Systems. Kluwer Academic Publishers. 1999.

[24] S.X. Ding, Model-based Fault Diagnosis Techniques: Design Schemes, Algorithms, and Tools. 1st ed. Springer. Berlin Heidelberg. ISBN: 978-3540763031. 2008.

[25] J. Bryan, "Keeping it cool: A look at causes of motor overheating," Electrical Apparatus Service Association, Inc, www.easa.com, March 2015, pp. 1-5.

[26] A.R. Mohanty, S. Fatima, "Shaft misalignment detection by thermal imaging of support bearings," IFAC-PapersOnLine, vol. 48, no. 21, 2015, pp. 554-559

[27] Armando Guadalupe Garcia-Ramirez, Luis Alberto MoralesHernandez, Roque Alfredo Osornio-Rios, Juan Primo Benitez-Rangel, Arturo Garcia-Perez, Rene de Jesus Romero-Troncoso, "Fault detection in induction motors and the impact on the kinematic chain through thermographic analysis", Electric Power Systems Research, Vol. 114, Sep. 2014, pp. 1-9.

[28] Y. P. Aksenov, I. V. Yaroshenko, G. Noe and A. V. Andreev, "On-line diagnostics technology and repair results for medium voltage motors," 2009 IEEE International Symposium on Diagnostics for Electric Machines, Power Electronics and Drives, SDEMPED, Cargese, 2009, pp. 1-7.

[29] P. Karvelis et al., "An automated thermographic image segmentation method for induction motor fault diagnosis," IECON 2014 - 40th Annual Conference of the IEEE Industrial Electronics Society, Dallas, TX, 2014, pp. 3396-3402.

[30] Z.M. Zhang, B.K. Tsai, G. Machin, Radiometric Temperature Measurements, Academic Press, Oxford, 2010.

[31] D.P. Jones, Biomedical Sensors, Momentum Press, New York, 2010.

[32] R. Rinaldi, Infrared devices: short history and new trends, in: C. Meola (Ed.), Infrared Thermography Recent Advances and Future Trends, Bentham eBooks, 2012, pp. 29-59.

[33] J. Snell, R.W. Spring, The new approach to prioritizing anomalies found during thermographic electrical inspections, in: Proceedings of the SPIE 5073, 2003, pp. 222-230.

[34] R.N. Wurzbach, R.G. Hammaker, Role of comparative and qualitative thermography in predictive maintenance, in: Proceedings of the SPIE 1682, 1992, pp. 3-11.

[35] Y.C. Chieh, L. Yao, Automatic diagnostic system of electrical equipment using infrared thermography, in: Proceedings of the International Conference of Soft Computing and, Pattern Recognition, 2009, pp. 155-160.

[36] T.M. Lindquist, L. Bertling, R. Eriksson, Estimation of disconnector contact condition for modeling the effect of maintenance and ageing, in: Proceedings of the Russia Power Tech., 2005, pp. 1-7.

[37] Standard for Infrared Inspection of Electrical Systems \& Rotating Equipment, Infraspection Institute, 2008.
[38] ASTM, ASTM E 1934: Standard Guide for Examining Electrical and Mechanical Equipment with Infrared Thermography, West Conshohocken, Pennsylvania, ASTM International, 2005.

[39] NFPA, NFPA 70B: Recommended Practice for Electrical Equipment Maintenance, Quincy, Massachusetts, National Fire Protection Association, 2006.

\section{BIOGRAPHIES}

David López Pérez was born in 1974 in Ciudad Real, Spain. He earned his Bachelor's degree in Industrial Engineering after graduating from the Universidad Politécnica of Jaén (Spain), in 2003. His professional career, as well as his position as Head of Maintenance at MEISA has helped him to gain considerable knowledge and experience within the field of predictive, preventive and corrective maintenance. $\mathrm{He}$ is a Level 1 Certified Thermographer as per ITC. In addition to that, David completed a Master of Chemical Engineering and Environmental Management at the UCLM in 2006, as well as a Master of Industrial Maintenance Management with the COIIM (Engineering Society) in 2013.

Jose A. Antonino-Daviu (S'04, M'08, SM'12) received his M.S. and $\mathrm{Ph}$. D. degrees in Electrical Engineering, both from the Universitat Politècnica de València, in 2000 and 2006, respectively. He also received his Bs. in Business Administration from Universitat de Valencia in 2012. He was working for IBM during 2 years, being involved in several international projects. Currently, he is Associate Professor in the Department of Electrical Engineering of the mentioned University, where he develops his docent and research work. He has been invited professor in Helsinki University of Technology (Finland) in 2005 and 2007, Michigan State University (USA) in 2010, Korea University (Korea) in 2014 and Université Claude Bernard Lyon 1 (France) in 2015. He is IEEE Senior Member since 2012 and he has published over 140 contributions, including international journals, conferences and books. He is also Associate Editor of IEEE transactions on Industrial Informatics and has been Guest Editor in IEEE transactions on Industrial Electronics. He was General Co-Chair of IEEE SDEMPED 2013. 